\title{
Modul Sistem Parkir Kendaraan Roda 4 Menggunakan PLC OMRON CPM-1A
}

\author{
Suhaedi \\ Jurusan Teknik Elektronika \\ Politeknik Negeri Balikpapan \\ Jl. Soekarno Hatta Km.8 Balikpapan Tlp. (0542) 860895 Fax. 861107 \\ Email: suhaedi_bpp@yahoo.co.id
}

\begin{abstract}
Now the current number of transportations such as cars are increasing, consequently and more transportations, the more solid as well for the car park area. The problem in this situations is the comfort by worried motorists. Therefore presented in this thesis about the planning that has been done that is making an example of a model where an automatic car parking area which can be controled of its capacity. The example of model an automatic parking area is a miniature as eight centimeters high, four centimeters wide and fifty centimeters long and can accommodate four cars as many as nine cars. Manufacture of miniature automatic car parking is to use actuators such as DC, many infrared sensors, some of the photo diode sensors, relay and limit switches. Programmable logic control (PLC) is used as a controller that control all hardware. To display information, it uses an indicator light marked "FULL" and "EMPTY". The result of test is performed by running an automatic car parking system and the system can function properly and ready in use.
\end{abstract}

Keyword : automatic car parking, capacity, programmable logic control, infrared and photo diode sensor, actuator, limit switch.

\begin{abstract}
Abstrak
Saat ini jumlah kendaraan seperti mobil semakin meningkat, akibatnya semakin banyak kendaraan maka semakin padat juga untuk area tempat parkir mobil. Permasalahannya kenyamanan sangatlah di risaukan oleh para pengendara mobil. Karena itu pada tugas akhir ini dipaparkan tentang perancangan yang telah dilakukan yaitu pembuatan sebuah contoh model tempat area parkir mobil otomatis yang dapat di kontrol kapasitasnya. Contoh model area parkir otomatis ini berupa miniatur setinggi $15 \mathrm{~cm}$, lebar $40 \mathrm{~cm}$ dan panjang $50 \mathrm{~cm}$ juga dapat menampung kendaraan mobil roda empat sebanyak sembilan kendaraan. Pembuatan miniatur parkir mobil otomatis ini menggunakan penggerak seperti motor DC juga beberapa sensor infra merah, photo diode, relai dan limit switch. Programmable Logic Control (PLC) digunakan sebagai kontroller yang mengontrol semua perangkat keras. Untuk displai informasi mengunakan sebuah indikator lampu bertulisan "FULL" dan "EMPTY”. Dengan hasil pengujian yang dilakukan dengan menjalankan sistem area parkir mobil otomatis dan sistem dapat berfungsi dengan baik dan siap digunakan.
\end{abstract}

Kata kunci : Parkir mobil otomatis, kapasitas, PLC (Programmable Logic Control), Sensor Infra merah dan Foto dioda, Penggerak, Limit switch.

\section{Pendahuluan}

\subsection{Latar Belakang}

Perkembangan ilmu pengetahuan dan teknologi saat ini di bidang elektronika sangat pesat, terutama dalam teknologi rancang bangun sistem kontrol yang dapat mempengaruhi kehidupan masyarakat untuk melangkah lebih maju (modernisasi), berfikiran praktis, dan simple. Pembuatan peralatan-peralatan serba otomatis yang mengesampingkan peran manusia sebagai subyek pekerjaan telah banyak ditemukan.

Dewasa ini hampir semua bidang industri dan bidang lainnya menggunakan
Programmable Logic Controller (PLC), sebagai alat kontrol lift 3 lantai pada rumah sakit, sehingga pasien yang kamarnya di lantai atas diangkut melalui lift, alat pengaman pintu gerbang dengan menggunakan password dari handphone maupun dari tombol manual yang berbasis PLC, simulasi pintu garasi mobil otomatis berbasis PLC (programmable logic control). Untuk meningkatkan kualitas manusia dan menyelaraskan kemajuan teknologi control agar dapat ditransfer, perlu diupayakan modul pembelajaran yang terkait dengan sistem kontrol agar 
kebutuhan sumber daya manusia yang kompeten dan menguasai kontrol terpenuhi.

\subsection{Rumusan Masalah}

Berdasarkan kondisi yang ada maka timbul permasalahan yaitu bagaimana merancang dan membuat sebuah alat parkiran kendaraan roda empat yang kapasitasnya terkontrol secara otomatis yang menggunakan sistem kontrol PLC dan akan bekerja ketika ada sebuah kendaraan mobil yang masuk ataupun keluar dari area parkiran dengan otomatis akan menaikkan dan menurunkan pintu portal parkiran.

\subsection{Batasan Masalah}

Berdasarkan uraian diatas, maka dapat dirumuskan permasalahan sebagai berikut:

1. Bagaimana perancangan modul pembelajaran sistem parkir kendaraan roda 4 dengan menggunakan PLC OMRON CPM$1 \mathrm{~A}$

2. Bagaimana proses pembuatan modul pembelajaran sistem parkir kendaraan roda 4 dengan menggunakan PLC OMRON CPM$1 \mathrm{~A}$

3. Bagaimana cara melakukan pengujian modul pembelajaran sistem parkir kendaraan roda 4 yang telah dibuat

\subsection{Tujuan}

Tujuan penelitian adalah :

1. Merancang modul pembelajaran sistem parkir kendaraan roda 4 dengan menggunakan PLC.

2. Membuat modul pembelajaran sistem parkir kendaraan roda 4 dengan menggunakan PLC.

3. Melakukan uji coba modul pembelajaran sistem parkir kendaraan roda 4 dengan menggunakan PLC.

\subsection{Manfaat}

Manfaat hasil penelitian ini adalah:

1. Memberikan gambaran tentang proses control melalui modul pembelajaran.
2. Keunggulan sumber daya manusia dalam menggunakan PLC untuk mengontrol sistem parkir kendaraan roda

3. Memberikan sumbangan bagi kemajuan IPTEKS berupa diperolehnya inplementasi PLC sebagai suatu sistem kontrol.

\section{Metoda Penelitian}

Jenis penelitian adalah rancang bangun modul sistem parkir kendaraan roda 4 menggunakan Programmable Logic Control (PLC).

\subsection{Tempat dan Waktu Penelitian}

Tempat penelitian dilaksanakan di laksanakan di Lab. Elektronika Kampus Politeknik Negeri Balikpapan Jl. Soekarno Hatta km.8 Balikpapan Utara. Waktu penelitian dimulai 01 Juni 2012 sampai dengan 31 Agustus 2012.

\subsection{Metodologi Penelitian}

Diagram alir metode penelitian dapat ditunjukkan dalam Gambar 4.

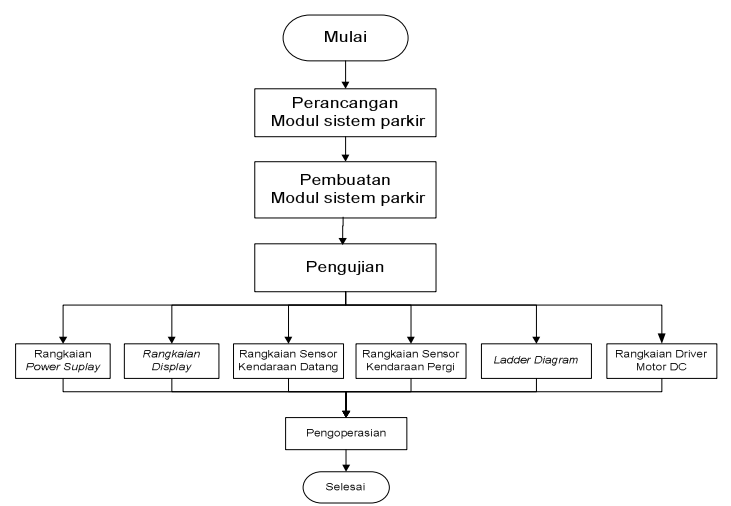

Gambar 4. Diagram Alir Metode Penelitian

\subsection{Perancangan}

Tahapan dari kegiatan perancangan ini meliputi, perancangan rangkaian elektronika, perancangan software dan perancangan mekanik Kegiatan penelitian adalah rancang bangun modul sistem parkir kendaraan roda 4 menggunakan Programmable Logic Control (PLC), tahapan dari kegiatan ini meliputi, perancangan rangkaian elektronika, 
perancangan software dan perancangan mekanik

\subsection{Perancangan Power Supply}

Power supply adalah suatu rangkaian yang digunakan untuk mengubah arus bolak balik menjadi arus searah (DC) seperti ditunjukkan pada Gambar 5.

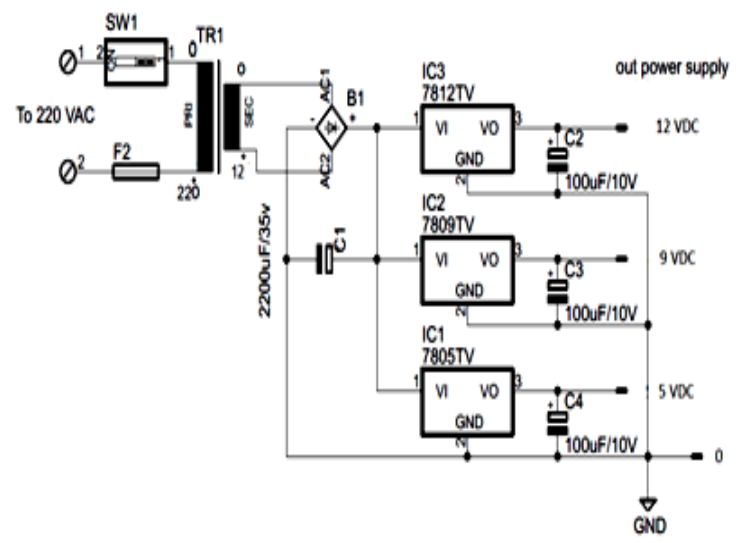

Gambar 6. Rancangan Rangkaian Power Supply

\subsection{Perancangan Driver Display Seven Segment}

Rangkaian ini berfungsi sebagai penghitung naik dan turun yang kemudian ditampilkan pada display seven segment. Komponen utama IC 74LS192 adalah sebuah up/down decade counter, yaitu sebuah komponen yang dapat melakukan pencacahan ( penghitung ) sampai 10 ( 0 sampai 9) naik dan turun. Dalam komponen 16 pin ini cukup banyak dapat dijumpai di toko komponen elektronika. 74LS192 dibangun dengan beberapa flip-flop JK dan gerbang-gerbang logik. IC 74LS47 merupakan dekoder BCD ke seven segment yang berfungsi untuk menyalakan sevent segment mode common anode. Dekoder BCD ke seven segment mempunyai masukan berupa bilangan BCD 4-bit (masukan A, B, C dan D). Bilangan BCD ini dikodekan sehingga membentuk kode tujuh segmen yang akan menyalakan ruasruas yang sesuai pada seven segment, seperti ditunjukkan dalam Gambar 6.

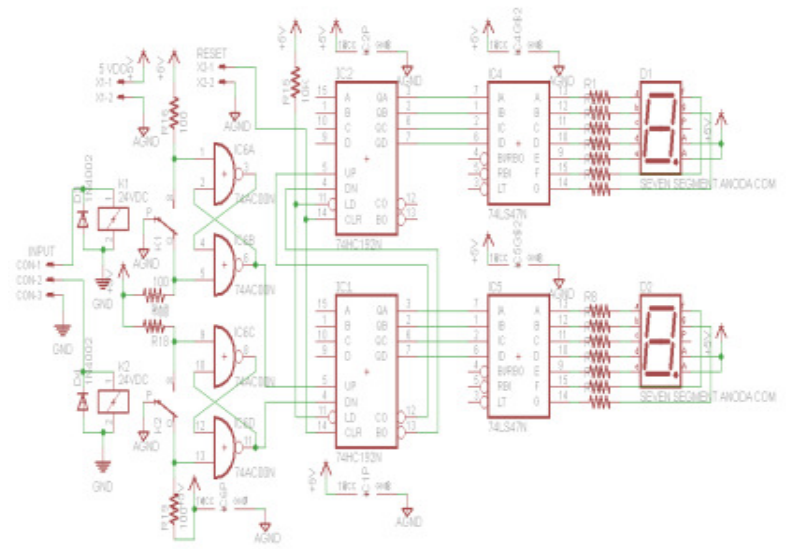

Gambar 6. Rangkaian Driver Seven Segment

\subsection{Perancangan Sensor Kendaraan Masuk dan Keluar}

Sensor yaitu sebuah komponen yang mendeteksi gejala-gejala suatu besaran fisik dan transduser yaitu suatu alat yang mengubah besar fisik ke besaran lain. Rangkaian sensor dalam penelitian ini terdiri dari rangkaian sensor yang digunakan untuk kendaraan masuk dan kendaraan keluar. Berikut gambar sebuah rangkaian sensor dan transduser.

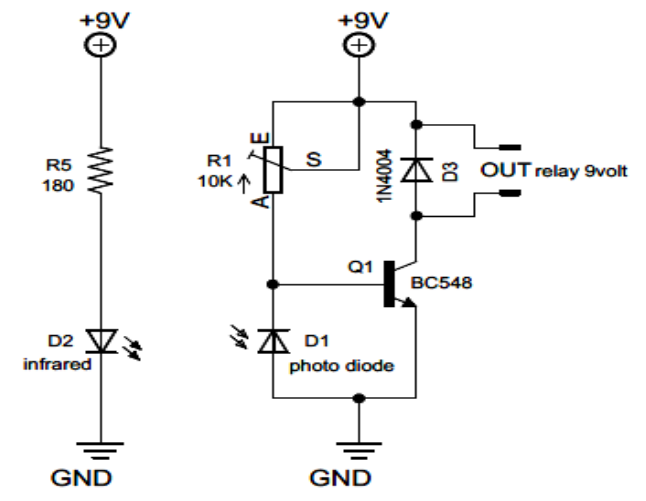

Gambar 7. Rancangan Rangkaian Sensor Kendaraan

\subsection{Perancangan Rangkaian Driver Motor DC}

Driver motor dc yaitu sebuah rangkaian yang dapat mengubah suatu kondisi dalam putaran motor, sedangkan pwm motor dc yaitu mengatur kecepatan pada motor pintu portal. Berikut rangkaian driver dan pwm motor DC : 


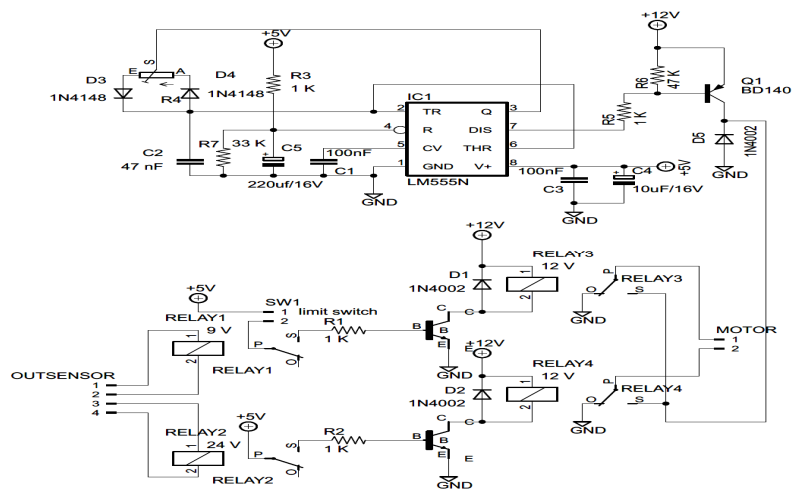

Gambar 8. Rancangan Rangkaian Driver Motor DC

\subsection{Perancangan Area Parkir}

Bahan utama yang digunakan yaitu dari fiber glass, akrilik dan almunium. Dengan sketsa sebagai berikut :

Panjang

Lebar

Tinggi

$$
: 40 \mathrm{~cm}
$$$$
: 15 \mathrm{~cm}
$$

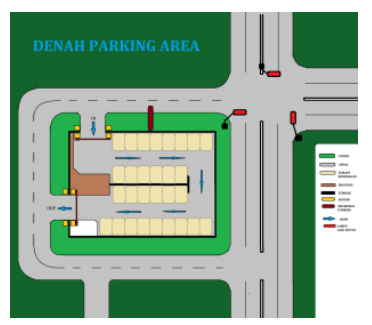

Gambar 10 Rancangan Denah Area Parkir

\section{Pemograman Ladder Diagram}

Program pengendali PLC ini menggunakan bahasa diagram ladder, diagram ini dibuat untuk sistem alat parkiran secara otomatis, adapun daftar input dan output, diagram dan mnemoniknya dapat di lihat dibawah ini :

Tabel 3.1 Daftar Alamat Masukan PLC

\begin{tabular}{|l|l|l|}
\hline Alamat & Keterangan & Fungsi \\
\hline 000.00 & $\begin{array}{l}\text { Sensor } \\
\text { masuk }\end{array}$ & $\begin{array}{l}\text { Untuk menghitung } \\
\text { (increment) }\end{array}$ \\
\hline 000.01 & $\begin{array}{l}\text { Sensor } \\
\text { keluar }\end{array}$ & $\begin{array}{l}\text { Untuk mengurangi } \\
\text { (dICrement) }\end{array}$ \\
\hline 000.02 & $\begin{array}{l}\text { Reset } \\
\text { Program }\end{array}$ & $\begin{array}{l}\text { Untuk } \\
\text { Mengkondisikan ke } \\
\text { awal (Move) }\end{array}$ \\
\hline 000.03 & $\begin{array}{l}\text { Limit switch } \\
\text { masuk }\end{array}$ & Untuk mereset (keep) \\
\hline
\end{tabular}

\section{Pengukuran dan Pengujian Alat} Power Supply

\begin{tabular}{|c|c|c|c|}
\hline No & $\begin{array}{c}\text { Power } \\
\text { Supply } \\
\text { (Volt) }\end{array}$ & $\begin{array}{c}\text { Tegangan } \\
\text { Masukan AC } \\
\text { (Volt) }\end{array}$ & $\begin{array}{c}\text { Keluaran Keluaran } \\
\text { DC } \\
\text { (Volt) }\end{array}$ \\
\hline 1. & 5 & 216 & 4,92 \\
\hline 2. & 9 & 216 & 8,86 \\
\hline 3. & 12 & 216 & 11,77 \\
\hline
\end{tabular}

Dari data hasil pengukuran dan pengujian serta dibandingkan dengan data sheet IC Regulator tersebut maka rangkaian power supply bekerja sesuai dengan perancangan dan dapat digunakan.

\section{Driver Display Seven Segment}

\begin{tabular}{|c|c|}
\hline Kendaraan Ke : & $\begin{array}{c}\text { Penunjukan } \\
\text { Display }\end{array}$ \\
\hline 1. & 1 \\
\hline 2. & 2 \\
\hline 3. & 3 \\
\hline 4. & 4 \\
\hline 5. & 5 \\
\hline
\end{tabular}

Dari hasil pengukuran dan pengujian driver display sevent segment setiap kendaraan masuk area parkir, display akan menunjukan angka sesuai dengan jumlah kendaraan yang masuk.

\section{Rangkaian Sensor Kendaraan}

\begin{tabular}{|l|c|c|c|}
\hline No & $\begin{array}{c}\text { Kondisi } \\
\text { Kendaraan }\end{array}$ & $\begin{array}{c}\text { Posisi Relay } \\
\text { Sensor Masuk }\end{array}$ & $\begin{array}{c}\text { Posisi Relay } \\
\text { Sensor Keluar }\end{array}$ \\
\hline 1. & $\begin{array}{c}\text { Kendaraan } \\
\text { Masuk }\end{array}$ & Terhubung & Putus \\
\hline 2. & $\begin{array}{c}\text { Kendaraan } \\
\text { Keluar }\end{array}$ & Putus & Terhubung \\
\hline
\end{tabular}

Dari data hasil pengukuran dan pengujian sensor kendaraan, relay akan terhubung saat kendaraan masuk ke area parkir dan relay pada sensor kendaraan keluar akan terhubung saat kendaraan meninggalkan area parkir, maka sensor kendaraan bekerja sesuai dengan perancangan dan dapat digunakan. 
Rangkaian Driver Motor DC Driver Motor DC

\begin{tabular}{|c|l|c|c|}
\hline No & $\begin{array}{l}\text { Kondisi } \\
\text { Kendaraan }\end{array}$ & $\begin{array}{c}\text { Posisi Relay } \\
\text { Sensor Masuk }\end{array}$ & $\begin{array}{c}\text { Kondisi } \\
\text { Palang Pintu }\end{array}$ \\
\hline 1. & $\begin{array}{l}\text { Kendaraan } \\
\text { Masuk }\end{array}$ & Terhubung & Naik \\
\hline 2. & $\begin{array}{l}\text { Kendaraan } \\
\text { Keluar }\end{array}$ & Putus & Turun \\
\hline
\end{tabular}

Dari data hasil pengukuran dan pengujian sensor kendaraan, relay pada sensor kendaraan masuk akan terhubung saat kendaraan masuk ke area parkir dan relay pada sensor kendaraan keluar akan terhubung saat kendaraan meninggalkan area parkir, maka sensor kendaraan bekerja sesuai dengan perancangan dan dapat digunakan.

\section{Pengujian Ladder Diagram}

Tabel 4.6 Hasil pengujian dan pengukuran Display

\begin{tabular}{|c|c|c|c|c|}
\hline \multirow{2}{*}{ No } & \multirow{2}{*}{ Saklar } & Kondisi relay & \multicolumn{2}{|c|}{ Display LED } \\
\cline { 4 - 5 } & NC & $\begin{array}{c}\text { Normaly } \\
\text { close }\end{array}$ & ON & OFF \\
\hline 1. & NULL & FUL \\
\hline 2. & NO & $\begin{array}{c}\text { Normaly } \\
\text { open }\end{array}$ & OFF & ON \\
\hline
\end{tabular}

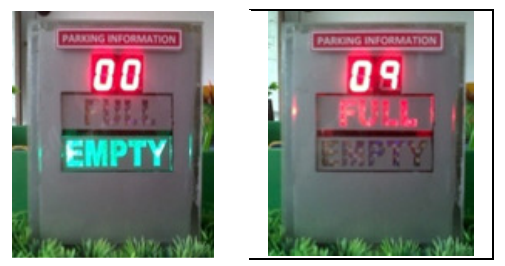

Gambar 11 Pengujian Display

\section{Kesimpulan dan Saran}

\subsection{Kesimpulan}

1. Telah dilakukan perancangan dan dibuat modul pembelajaran sistem parkir kendaraan roda 4 dengan menggunakan PLC OMRON CPM$1 \mathrm{~A}$.

2. Telah dilakukan uji coba modul pembelajaran sistem parkir kendaraan roda 4 dengan menggunakan PLC OMRON CPM
1A dengan kapasitas kendaraan sebanyak 10 .

\subsection{Saran}

Alat parkiran ini belumlah sempurna karena sensor masih mendeteksi berbagai macam gangguan seperti manusia, hewan dan benda-benda lainnya dalam membuka pintu portal. Adapun solusi yang akan mengatasi masalah tersebut, maka untuk mendeteksi apakah benar kendaraan atau bukan, perlulah penambahan sebuah sensor tekanan untuk mendeteksi bobot atau berat sebuah kendaraan, dan sensor tekanan dapat di setting minimum dan maksimumnya sesuai dengan kondisi kendaraan dilapangan.

\section{Daftar Pustaka}

[1]. Albert Paul Malvino. (1985) : Prinsip-Prinsip Elektronika, Edisi Ketiga, Jilit 1. Jakarta : Erlangga

[2]. Dedy Rusmadi dan Deni Prihadi. (2007) : Belajar Rangkaian Elektronika Tanpa Guru. Bandung : CV.Del Fajar.

[3]. Franky Chandra dan Deni Arifianto. (2010) : Jago Elektronika. Surabaya : PT. Kawan Pustaka.

[4]. Iwan Setiawan. (2005) : Programmable Logic Controller (PLC) dan Teknik Perancangan Sistem Kontrol. Semarang: Andi.

[5]. Wiliam Bolton. (2003) : Program Logic Control (PLC), Sebuah Pengantar, Edisi Ketiga. Jakarta : Erlangga 